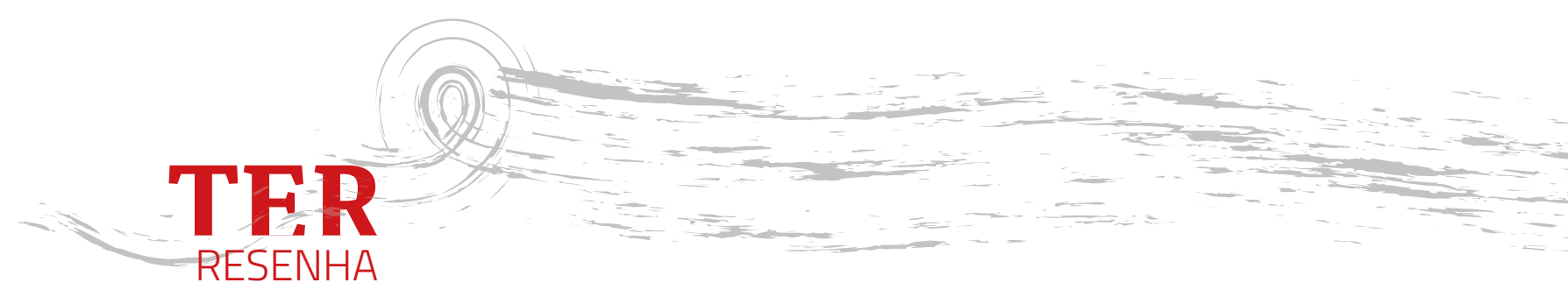

Universidade de São Paulo,

FERNANDA ARÊAS PEIXOTO

São Paulo, Brasil.

\title{
CORPO E ALMA DA ARTE MODERNA EM SÃO PAULO
}

Paulo Mendes de Almeida. 2014. De Anita ao museu. O modernismo, da primeira exposição de Anita Malfatti à primeira Bienal. São Paulo, Terceiro Nome, 251p. il. P\&b, color.
O movimento modernista, que 1922 e a Semana de Arte Moderna expressam e simbolizam, está longe de ser evento adormecido, desses que restam nas páginas dos compêndios históricos a espera que um olhar curioso que os faça reintegrar o curso dos dias. Justo o contrário: as performances artísticas que tomaram o Teatro Municipal de São Paulo, entre 11 e 18 de fevereiro, continuam presentes, e muito presentes, nos debates sobre as artes no país, sobre a vida cultural na cidade de são Paulo, e também em efemérides e comemorações, as mais variadas.

A memória do movimento paulistano é ativada tanto pelos que sublinham o seu caráter disruptivo quanto por aqueles que tendem a enfatizar continuidades ou por outros que interpelam, criticamente, o cânone modernista. As querelas são muitas e se acumulam em uma série de estudos, livros e teses universitárias; uma busca rápida nos sites e bibliotecas é suficiente para nos inteirarmos das posições em jogo, não há necessidade de retomá-las aqui. Mas a menção aos debates envolvendo o modernismo de 1922 e seus desdobramentos parece oportuna para destacarmos o equilíbrio crítico de Paulo Mendes de Almeida, que acompanhou de perto aqueles anos. A serenidade desse observador, ator e comentador da vida artística na capital paulistana contrasta com posições arrebatadas e polêmicas que tendem a acompanhar, até hoje, as retomadas do movimento e de seus principais protagonistas. 
Poeta, jornalista, crítico de arte e de literatura, um dos fundadores da Sociedade Pró-Arte Moderna, além de diretor artístico do Museu de Arte Moderna e secretário da Bienal (a partir de 1958 e 1959, respectivamente), Paulo Mendes de Almeida (1905-1986) foi, sem dúvida, uma figura fundamental nas artes em São Paulo, e De Anita ao museu, por ele assinado, é um clássico no sentido pleno do termo. Firmemente ancorado nos anos 1950, o livro atravessa os tempos, não apenas por constituir fonte indispensável sobre o período, mas por lograr capturar a atmosfera da época, embalados que somos pelo tom do cronista, cujas memórias e estilo arguto fazem reviver espaços, cenas e personagens; razão suficiente para saudarmos a reedição do volume de 1976 (da coleção Debates, editora Perspectiva), que ampliara o primeiro, de 1961, com treze novos capítulos. Mas, vale observar, o livro atual, apresentado pela escritora, editora e tradutora Ana Luísa Martins, não é mero relançamento do livro de 1976; acrescido de notas explicativas, imagens e documentos que valorizam o texto, este volume pode ser visto como uma edição ampliada.

Reunindo artigos publicados no "Suplemento Literário" de $O$ Estado de $S$. Paulo, entre 1958 e 1965, o livro desenha um percurso preciso, como o próprio título indica: parte da célebre exposição de Anita Malfatti, de 1917, considerada o elemento propulsor do movimento de 1922, e chega à criação do Museu de Arte Moderna em 1949, descrevendo um arco temporal ou uma "evolução", como quer o autor, que contribui para a história das artes no país, sem ser pesquisa histórica, sistematicamente construída. De fato, as "notas" ou "apontamentos" de Paulo Mendes de Almeida mais próximos estão do registro memorialístico, encadeados por tom de crônica e testemunho, o que confere ao texto vida e ritmo particulares. "Quem viveu esses dias, há de se lembrar que tudo cheirava a revolução", diz ele, transportando o leitor para a ambiência do período e colocando-o em contato com um rol de figuras, algumas ilustres, outras quase desconhecidas. Somos apresentados a pintores, escritores, escultores e arquitetos; a críticos, jornalistas, mecenas e colecionadores; a desenhistas, coreógrafos, cenógrafos e ilustradores; a homens e mulheres; nacionais e estrangeiros, de diversas procedências. Esta é uma das qualidades notáveis desses relatos de Paulo Mendes de Almeida: a maneira como alarga e diversifica o cenário artístico paulistano em geral e os anos modernistas, em particular. Ao fazê-lo, o escritor não apenas auxilia a melhor compreensão de uma época, como fornece um manancial de fontes e sugestões para novas pesquisas e investidas analíticas sobre temas aparentemente esgotados.

Aos perfis que se sucedem ao longo da narrativa soma-se a apresentação das agremiações que eles criaram ou as quais se filiaram: a Sociedade Pró-Arte-Moderna (1932), o Clube dos Artistas Modernos (1932), o 1ํ $2^{\circ} \mathrm{e}$ $3^{\circ}$ Salões de Maio (1937, 1938 e 1939), a Família Artística Paulista (1937), o Grupo Santa Helena (1934), os Salões do Sindicato dos Artistas Plásticos (1938-1949). Tais associações são descritas não apenas em função de 
obras e exposições, mas de atividades mais amplas que fomentaram: conferências, solenidades, bailes, saraus, festas e concertos. Somos, assim, convidados a conhecer não somente os artistas, mas também os organizadores e patrocinadores dos eventos, as revistas e catálogos, e mesmo certas reações do público, o que nos endereça a dimensões mais recônditas e, salvo engano, menos tratadas pelos estudiosos da arte. E, como se não bastasse, a vida artística na São Paulo dos anos 1930, 1940 e 1950, que os textos de Paulo Mendes de Almeida reconstroem, é inseparável da fisionomia urbana, o que é outra das contribuições do livro, que revela a cidade de São Paulo nesses anos, em função do esboço de uma cartografia das artes, letras e espaços a eles dedicados: galerias de arte, bares, cinemas, teatros, edifícios, bibliotecas e cafés.

A consideração de uma sociabilidade artístico-cultural urbana específica combina-se ao exame de debates estéticos e críticos, que iluminam fissuras no interior dos grupos, dotando-os de densidade renovada. Querelas entre "acadêmicos" e "modernos"; discussões entre figurativistas e abstracionistas; bafafás em torno de Portinari, entre outras polêmicas, atravessaram os coletivos, sem necessariamente desfazê-los; afinal, foram discordâncias e diferenças que conferiram vida própria a cada um deles. Nesse sentido, falando dos encontros do CAM, Paulo Mendes indica como as controvérsias animavam o grupo: "as discussões ferviam à medida que os copos se esvaziavam, em torno das mesas que Sava e Pacha iam servindo. Muitas vezes, improvisavam-se festas, danças que entravam ruidosas pela madrugada adentro" (p. 81). Dissensões tomaram (e impulsionaram) a própria Semana de Arte Moderna, afirma ele; vista do ângulo das artes plásticas, o certame esteve marcado por "heterogeneidade, contradições e incoerências", por posições mais ou menos modernas que conviveram no interior do movimento. 0 mesmo pode ser dito de seus desdobramentos. Se alguns círculos e personagens (Flávio de Carvalho, por exemplo) procuraram alimentar posturas de rebeldia, outros, como a Família Artística Paulista, afastavam-se da própria designação "modernista" pela retomada deliberada da tradição artística. A constatação não leva o autor a menosprezar as contribuições desses grupos diante da tarefa de pensar a constituição de um ambiente artístico moderno em São Paulo, o que nos leva, mais uma vez, ao equilíbrio crítico de Paulo Mendes. Em suas palavras:

“[...] a Família Artística Paulista veio afirmar uma louvável crença na imprescindibilidade do métier, da apuração dos elementos técnicos e formais da arte de pintar, o que significou um poderoso estímulo à formação de uma consciência profissional nos jovens artistas brasileiros, especialmente nos de São Paulo, e representou assim, e sem dúvida, um importante passo na evolução da arte moderna no país, entendida em sentido mais amplo" (p. 113). 
O tom sereno e o compromisso em lançar uma perspectiva ampliada e nuançada sobre a arte moderna em São Paulo não exime o autor dos juízos críticos (quando, por exemplo, marca suas distâncias em relação às leituras de Mário de Andrade sobre o grupo Santa Helena), nem da defesa de um argumento central: o lugar do Museu de Arte Moderna como ápice de um processo de germinação artística, que teve início em 1922 e que se consolidou ao longo dos anos. Nesse sentido, o livro pode ser lido como uma pré-história do museu, como o esboço de um quadro retrospectivo, como diz o seu autor, que deixa ver as condições de possibilidade da nova instituição (constituída oficialmente em 1948 e cuja sede data de 1949) e da $1^{\text {a }}$ Bienal (1951), tributárias de um ambiente artístico que acolhe progressivamente a arte moderna. Assim que os cinco últimos capítulos do livro funcionam como o ponto de partida da análise, reenviando o leitor para o início.

Quando o assunto é o MAM e a Bienal, aí também, Paulo Mendes de Almeida exercita o seu talento descritivo, trazendo à tona os detalhes que envolveram os empreendimentos, atento as figuras de proa assim como as de bastidor. Nos segmentos finais do volume, encontram-se arrolados os nomes de todos os signatários da escritura pública que constituiu o museu; os termos de seu estatuto; a equipe diretora e aquela encarregada da organização; as reações públicas a sua criação; as primeiras exposições e a lista dos participantes, nacionais e estrangeiros. Descrições, todas elas, mobilizadas para enfatizar o caráter desbravador da $1^{\text {a }}$ Bienal e de seus organizadores a quem "coube a abertura da picada em plena mata". o caráter inaugural do empreendimento ganha realce diante dos sinais de declínio que ele já identifica em 1963, quando da abertura da 7ªienal, então desvinculada do MAM e sob a responsabilidade da Fundação Bienal recém-criada.

Não há como recuperar na íntegra o conteúdo dos textos que compõem este De Anita ao museu, sua riqueza do ponto de vista descritivo ou todas as pistas que lança a futuros pesquisadores. Assim sendo, só nos cabe deixar registrado o convite à leitura (ou à releitura) da narrativa rica e saborosa de Paulo Mendes de Almeida que expande o nosso conhecimento e juízos sobre a arte moderna no país.

\section{FERNANDA ARÊAS PEIXOTO}

Professora Titular do Departamento de Antropologia da USP, pesquisadora do CNPq (Ministério da Ciência e Tecnologia), coordenadora do ASA artes, saberes, antropologia; autora, entre outros, de Diálogos brasileiros:

recebido

12.01 .2018

aprovado

19.01.2018 uma análise da obra de Roger Bastide (Edusp/Fapesp, 2000) e A viagem como vocação: itinerários, parcerias e formas de conhecimento (Edusp, Fapesp, 2015), Ciudades sudamericanas como arenas culturales, organizado com Adrián Gorelik (Siglo XXI, 2016). 